\title{
Avoidance differences between rats and gerbils
}

\author{
SUY L. OSBORNE, WILLIAM F. CAUL, and RICHARD VANSTRUM \\ V'anderbult University, Nashville, Tennessee 37240
}

\begin{abstract}
Gerbils and rats learned equally well to discriminate the lighted, safe arm from the unsafe arm during $Y$-maze avoidance trials. Gerbils, however, were inferior to rats in initiating this response in time to avoid shock. Two subsequent experiments on passive avoidance did not support the interpretation of these data based on a greater incidence of shock-induced activity suppression in gerbils. In both experiments, gerbils required more shocks than rats to learn a staying response, indicating a pronounced locomotor response bias in gerbils that is not compatible with the required passive avoidance response. A fourth experiment, using a shuttlebox, found that the relative active avoidance performance by these species depends upon whether intertrial responses are permitted and punished. When they are, gerbils are inferior to rats, since their high level of locomotor responding is not compatible with the behavior required, i.e., staying during the intertrial interval and running during the CS-US interval. On the other hand, gerbils are not inferior when intertrial responses are prohibited, since their locomotor bias is not punished and is compatible with the required avoidance response.
\end{abstract}

It was suggested by Walters and Abel (1971) that rats perform passive avoidance better than gerbils while gerbils perform active avoidance better than rats. This observation derives support from a number of comparisons of these species in avoidance tasks. With regard to active avoidance learning, gerbils were superior to rats in barpress (Walters, Pearl, \& Roger, 1963) and two-way shuttlebox (Ashe \& McCain, 1972) avoidance tasks. In contrast, rats were superior to gerbils in passive avoidance tasks using shock (Galvanni, Riddell, \& Foster, 1975; Walters \& Abel, 1971) and nonshock aversive stimulation (Lippman, Galosy, \& Thompson, 1970). Recently, Galvanni et al. (1975) have provyded evidence that these species differences in passive avoidance are attributable to a greater tendency for exploration in gerbils than in rats.

The present series of studies compared these species further in both active and passive avoidance tasks in an attempt to elaborate the basis for these observed species avoidance differences. Experiment I compared the species in a discriminated $Y$-maze task which not only requires a response within the CS.US interval but also a discrimination between the safe (lighted) and unsafe (unlighted) compartments to avoid shock. An animal's performance can thus be described not only in terms of the number of escape vs. avoidance responses made, as is typically done with shuttlebox data, but also in terms of the number of correct vs. incorrect discriminations. Barrett, Leith, and Ray (1973) have asserted that with this additional, independent measure of learning, an analysis of avoidance performance in the $Y$-maze can assess the extent to which associative or motivational factors mediate the avoidance response.

This approach is illustrated in a study by Caul and Barrett (1973) in which avoidance differences between four strains of rats were investigated in both shuttlebox

The first author is now with the Department of Psychology, University of North Carolina at Charlotte, UNCC Station, Charlotte, N.C. $\mathbf{2 8 2 2 3}$ and Y-maze tests. The ordinal relationship among the strains in avoidance performance was found to be the same in both tasks. However, in the Y-maze all strains learned the brightness discrimination problem equally well. This fact, plus the additional findings that the better avoiding strains were more active in the shuttlebox between trials and showed more locomotor activity during the CS-US interval in the Y-maze, supported a motivational interpretation of the data: Differences in avoidance behavior between the strains were due to strain differences in unconditioned response to shock rather than to associative factors per se. Specifically, poor avoidance in two strains of rats was determined by a marked degree of shock-induced behavioral suppression which prevented the performance of the required active-avoidance response, whereas superior ayoidance was related to the absence of this incompatible strain-specific response to shock. This interpretation is consistent with recent arguments which emphasize the important interaction between an animal's species-specific response repertoire and the precise nature of the experimental task (Bolles, 1970; Shettleworth, 1972). Caul and Barrett demonstrated that this principle is equally important when considering differences in task performance among strains of the same species.

Since the $\mathrm{Y}$-maze was useful in identifying variables accounting for differences among rat strains in avoidance behavior, it was chosen for use in the present study to aid in identifying factors accounting for reported species differences in avoidance behavior between gerbils and rats. Since differences in avoidance performance among rat strains were found to be related to differences in degree of activity suppression produced by shock, activity was recorded in the present study in a nonshock environment immediately after each Y-maze session. It was thought that differences between rats and gerbils in reactivity to shock during the $Y$-maze avoidance trials might be reflected in the postavoidance session activity period. In addition, since it has been 


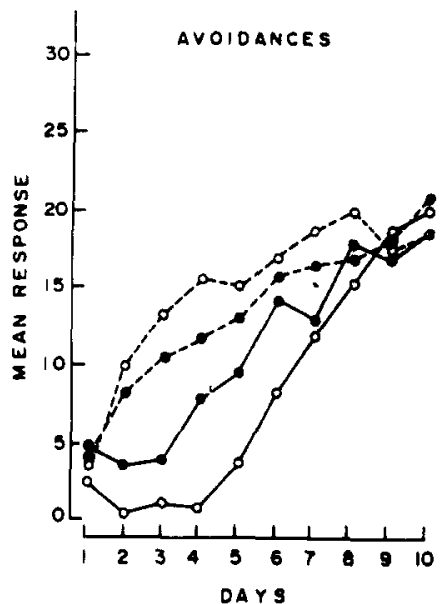

DAYS

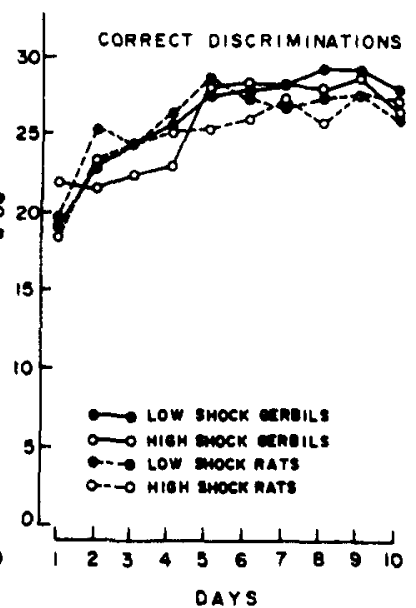

Figure 1. Mean avoidances and mean correct discriminations for rats and gerbils as a function of shock intensity and training session. reported that rats learn a brightness discrimination faster than gerbils in an appetitive situation (Wise \& Parker, 1968), the discrimination performance in the aversive $Y$-maze was of interest in assessing the generality of this finding.

\section{EXPERIMENT I}

\section{Method}

Subjects. Since previous comparisons of the behavior of rats and gerbils have employed Sprague-Dawley rats from Holtzman Company, Madison, Wisconsin (Galvanni et al., 1975; Lippman et al, 1970; Walters \& Abel, 1971), 12 male animals of this strain from Holtzman and 12 male Mongolian gerbils (Meriones unguiculatus) from Tumblebrook Farms, Brant Lake, New York, were used in the present study. The 90-day-old rats weighed from $325-365 \mathrm{~g}$ and were housed individually in standard laboratory cages. Gerbils, also 90 days old, we1ghed $52-66 \mathrm{~g}$ and were housed in parrs in $175 \times 28 \times 12.5 \mathrm{~cm}$ plastic cages provided with straw beddıng. All anımais receıved food and water ad lib Testing was done during the lighted phase of the light-dark cycle maintained in the animal room.

Apparatus. Two automated symmetrical Y-mazes used previously by Caul and Barrett (1973) were employed. Each maze had arms $27.9 \mathrm{~cm}$ deep $\times 10 \mathrm{~cm}$ wide $\times 9.5 \mathrm{~cm}$ high extending from a triangular choice area $10.2 \mathrm{~cm}$ on each side. Walls and tops of the mazes were constructed of opaque Plexiglas and the floor was composed of stainless steel rods, $.3 \mathrm{~cm}$ in diameter and spaced $1.9 \mathrm{~cm}$ apart center to center. A lowintensity $28-\mathrm{V}$ dc light behind white frosted Plexiglas at the end of each arm served as the stimulus. Footshock (either .75 or $1.5 \mathrm{~mA}, 60 \mathrm{~Hz} \mathrm{ac}$ ) was delivered to the grid floor through a Foringer Model 1925 shock scrambler regulated by an autotransformer. Responses made into an arm of the maze were monitored by photocells placed $5 \mathrm{~cm}$ inside the entrance of each arm. The two mazes, separated by a plywood partition, were in a darkened room adjacent to the control room. White noise at $70 \mathrm{~dB}$ was used to mask extraneous laboratory noises.

Two Animex activity meters (AB Farad, Type DS) with auxiliary printout devices were used in a second experimental room. Plastic cages, $24 \times 36 \times 15.5 \mathrm{~cm}$, with plastic screen covers were used on top of the activity counters. Activity counts generated by an animal's movement within the plastic cage were recorded at 1 -min intervals during the 15 -min activity sessions. The meters were housed in a soundproof chamber.

Procedure. The 12 rats and 12 gerbils were randomly assigned to groups of six anımals each. Low Shock gerbils and Low Shock rats received a $.75-\mathrm{mA}$ shock, while High Shock gerbils and High Shock rats received a $1.5-\mathrm{mA}$ shock in the Y-maze.
All animals were first tested for 4 days in the Animex activity counters. A run consisted of two animals from one of the groups being taken from their home cages, placed in a carrier, and transported to a soundproof room containing the two Animex activity meters. Activity was recorded for $15 \mathrm{~min}$, after which the animals were taken back to their home cages. Starting on the fifth experimental day and continuing for 10 consecutive days, the animals were given 30 trials of avoidance contitioning in the automated Y-maze followed by $15 \mathrm{~min}$ in the Animex activity apparatus.

Avoidance conditioning trals were initiated at 40 -sec intervals and begun by random switching of the stimulus light to one of the two previously dark arms of the Y-maze. Failure to avoid within $10 \mathrm{sec}$ resulted in shock onset, which the animal could terminate by entering the lighted arm. Entering a dark arm at any time except during the 10-sec CS-US interval resulted in shock which was terminated when the animal reentered the lighted arm. The following measures of the animals' performance were recorded after each block of 10 trials in the Y-maze: (a) avoidances-number of trials on which the animal avoided shock by reaching the lighted arm during the 10-sec CS-US interval; (b) correct discriminations -number of trials on which the animal chose the lighted safe arm in making its initial response (whether avoidance or escape); and (c) intertrial crosses-number of times animals ran from the lighted safe arm to a dark arm and were shocked during the intertrial interval.

\section{Results}

The analysis of activity data recorded during the 15 -min period on each of 4 days prior to the start of Y-maze training showed that rats produced more activity counts than gerbils $(F=7.07$, df $=1 / 20, p<.05)$. Neither the days nor Species by Days interaction factors were significant.

The number of activity counts for rats remained greater than for gerbils over the activity sessions which immediately followed each of the $10 \mathrm{Y}$-maze sessions $(F=17.16, \mathrm{df}=1 / 20, \mathrm{p}<.01)$. The analysis of these data also revealed a reliable Species by Days interaction $(F=2.41, \mathrm{df}=9 / 180, \mathrm{p}<.05)$, which reflects a greater decrease in activity over the 10 days for gerbils than for rats. The mean Day 1 and Day 10 activity counts for gerbils were 32.6 and 13.2 , respectively, while comparable means for rats were 42.2 and 37.1 . The shock intensity factor was not reliable $(\mathrm{F}=1.23 \mathrm{df}=1 / 20$, $\mathrm{p}=.28$ ) and failed to interact with species $(\mathrm{F}<1)$ 
or days $(\mathrm{F}=1.18, \mathrm{df}=8 / 180, \mathrm{p}=.31)$.

The left side of Figure 1 shows the mean number of avoidance responses for each of the $10 \mathrm{Y}$-maze conditioning days. As can be seen from the graph, the number of avoidance responses increased over days for all animals $(F=29.33, \mathrm{df}=9 / 180, p<.001)$, with the rate of increase being greater for rats than for gerbils $(F=3.21, d f=9 / 180, p<.01)$. Although Species by Shock Intensity and Species by Shock Intensity by Days interactions are suggested by the plot, neither interaction was significant in the analysis $(\mathrm{F}<1$ and $F=1.16, d f=9 / 180, p=.32$, respectively).

The analysis of correct discrimination data shown on the right in Figure 1 indicated that, in addition to the overall improvement over days $(F=48.00, \mathrm{df}=9 / 180$, $\mathrm{p}<.001)$, there was a reliable Species by Days interaction $(F=3.02$, df $=9 / 180, p<.01)$. Subsequent analyses showed that the discrimination performance of the High Shock gerbils over the first 5 conditioning days was the source of this interaction. While the High Shock gerbils made fewer correct discriminations than the other three groups over the first 5 days $(F=2.63$, $\mathrm{df}=4 / 80, \mathrm{p}<.05$ ), there was no difference among groups during the final 5 days of training $(\mathrm{F}=1.13$, $\mathrm{df}=4 / 80, \mathrm{p}<.35)$.

Figure 2 shows the within-session pattern of avoidance responding for each group. The major finding presented in Figure 2 is the reliable Species by Blocks interaction $(F=19.26, \mathrm{df}=2 / 40, p<.001)$. Subsequent analyses showed that whereas rats increased in avoidance performance over the three 10-trial blocks of a session $(F=13.51, \mathrm{df}=2 / 20, p<.001)$, the number of avoid- ance responses decreased over blocks for gerbils $(F=6.77, \mathrm{df}=2 / 20, \mathrm{p}<.01)$. The mean numbers of avoidance responses for each of the three 10-trial blocks averaged over days for rats were $3.58,4.92$, and 5.65 , while the comparable means for gerbils were $3.53,3.16$, and 2.92. As suggested by Figure 2, this general pattern was influenced by shock intensity and day (Species by Shock Intensity by Block by Days: $F=1.69$ $\mathrm{df}=18 / 360, \mathrm{p}<.05)$.

There were no overall differences in mean number of intertrial crosses between the species $(F<1)$ or shock intensities $(F=1.76, \mathrm{df}=1.20, \mathrm{p}=.20)$. In contrast to the rats, however, gerbils decreased in number of intertrial crosses across blocks $(F=44.71, \mathrm{df}=2 / 20$, $p<.001$ ), which accounts for the Species by Blocks interaction detected $(F=15.75, \mathrm{df}=2 / 40, \mathrm{p}<.001)$.

\section{Discussion}

As is apparent in Figùre 1, rats were superior to gerbils in avoidance acquisition in the Y-maze. Furthermore, the number of within-session avoidance responses increased for rats but decreased for gerbils. Thus, as the daily avoidance sessions progressed, the number of shocks received by rats decreased while the number of shocks received by gerbils increased.

Both species learned the discrimination problem of running to the lighted arm to avoid or escape shock. Although High Shock gerbils did not perform as well initially as the other three groups, the species differences in avoidance responding cannot be attributed to poorer discrimination learning by the gerbils. The right side of Figure 1 shows that Low Shock gerbils were indistin-

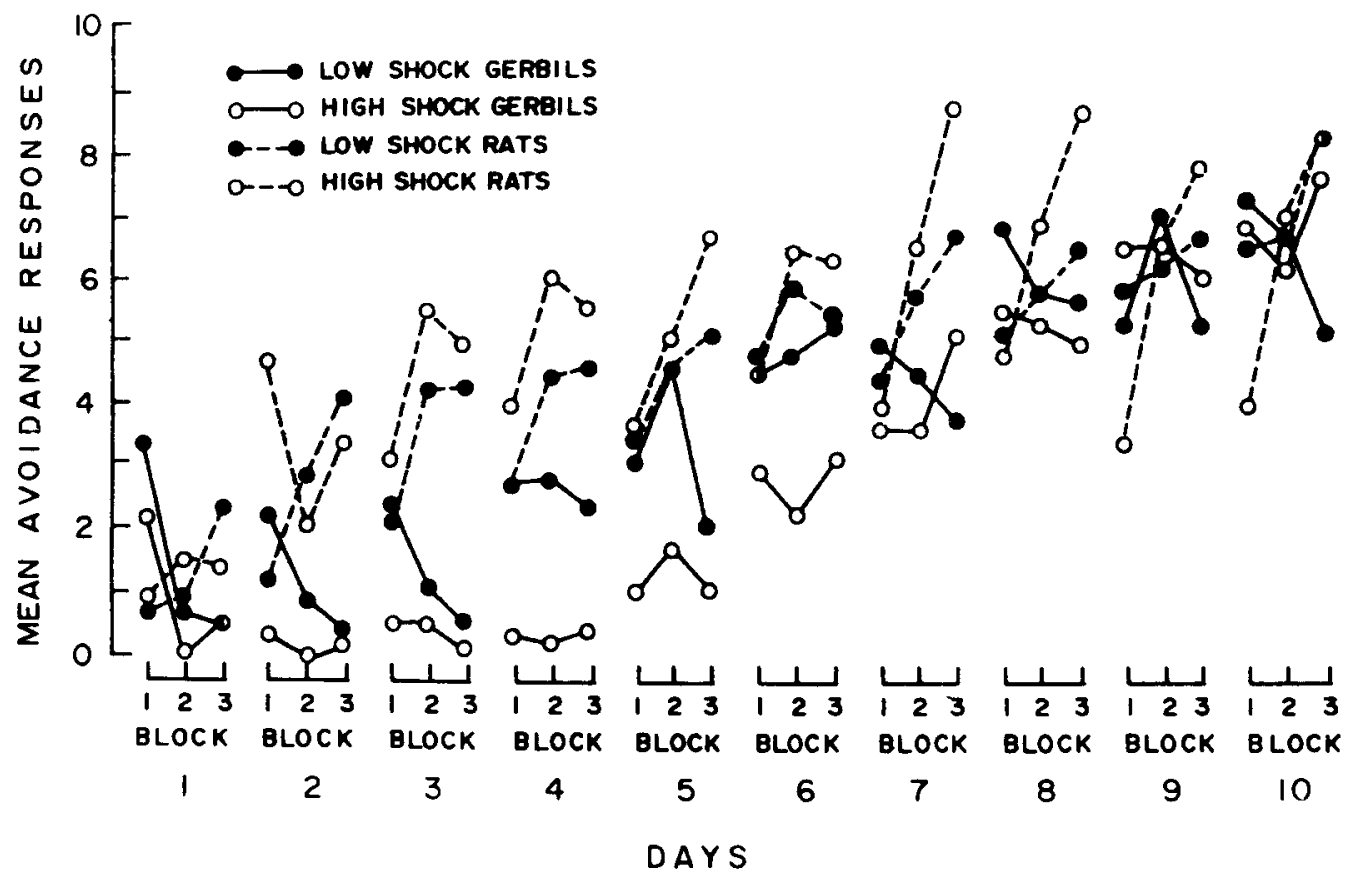

Figure 2. Mean avoidances for rats and gerbils as a function of 10-trial blocks for each training session. 
guishable from Low and High Shock rats in the number of correct discriminations made during the 10 days of training. Thus, the earlier finding of poorer brightness discrimination learning in the gerbil in an appetitive task (Wise \& Parker, 1968) is not general to the present avoidance procedure.

Interpretation of the postsession activity measure in terms of which species was more active following the avoidance trials is probably not appropriate, since the relative mass of an animal seemed to determine in part its activity count. In general, larger animals had higher activity counts. Gerbils did, however, show more of a decrease in activity over days than did rats, a finding probably independent of body mass. Gerbils also decreased in mean intertrial crosses over blocks, whereas rats did not.

These data were sufficiently similar to previous reports of strain differences in avoidance behavior in Y-maze tasks (Barrett et al., 1973; Caul \& Barrett, 1973) to suggest that the same variables determining these strain differences might also be producing species differences in avoidance responding in the present study. It was argued in those studies that strain differences in reactivity to shock produced the avoidance differences between the strains. Extending this view to the present data would suggest that gerbils made fewer avoidances than rats in the $\mathrm{Y}$-maze because of a greater degree of shock-induced suppression. This idea derives support from the findings that (a) gerbils tended to make fewer avoidance responses as each day's session progressed, whereas rats made more; (b) gerbils decreased in number of mean intertrial crosses over blocks, whereas rats did not; (c) gerbils decreased in postsession activity over days more than did rats; and (d) both species quickly learned the brightness discrimination problem, which suggests that gerbils are not inferior to rats in ability to learn the avoidance contingency.

\section{EXPERIMENT II}

The argument that the $\mathrm{Y}$-maze results are due to species differences in reaction to shock implies that gerbils should require fewer shocks than rats to reach a criterion of performance in a passive avoidance situation, since they are more sensitive to shock-induced activity decreases. This prediction, however, is not consistent with the findings reported by Walters and Abel (1971) or the general conclusion reached by Galvanni et al. (1975). Using 24-h train-test intervals, Walters and Abel found that gerbils required more shocks than rats to acquire a passive avoidance response of remaining in one side of a shuttlebox.

Since there was a $24-\mathrm{h}$ interval between each shock, however, any activity suppression to shock could have dissipated between sessions (cf. Steranka \& Barrett, 1973). Thus the findings of Walters and Abel may not reflect differences between rats and gerbils in reaction to shock, since the tran-test interval was too long. The present study compared the two species in a passive avoidance task with a $1-\mathrm{h}$ intertrial interval. It was expected that this procedure would permit assessment of the effects of species differences in unconditioned response to shock on passive avordance acquisition.

\section{Method}

Subjects. Twenty male Sprague-Dawley rats from the Holtzman Company, Madison, Wisconsin, and 20 male gerbils (Meriones unguiculatus) from the laboratory colony were used. The rats were $60-75$ days old and weighed $325-375 \mathrm{~g}$. The gerbils were 4-9 months old and weighed $45-70 \mathrm{~g}$. All animals were housed individually in standard lab cages during the study and received food and water ad lib. Testing was done during the lighted phase of the 12-h light-dark cycle maintaned in the animal room.

Apparatus. A two-compartment box with a center guillotine door served as the passive avoidance apparatus. It measured $55 \mathrm{~cm}$ long $\times 17.5 \mathrm{~cm}$ wide $\times 19.4 \mathrm{~cm}$ high. When raised, the guillotine door allowed a clearance of $13.7 \mathrm{~cm}$ from the grid floor. The safe compartment walls and side of the gullotine door were white, and the shock compartment walls and side of the door were black. The tops of both compartments were black. A low intensity $71 / 2-W$ light bulb was in the center of each compartment top, but only the bulb in the safe side was turned on.

Footshock (either $1.0 \mathrm{~mA}$ or $2.0 \mathrm{~mA}, 60 \mathrm{~Hz}$ ac) was delivered to the grid floor through a Foringer Model 1925 shock scrambler regulated by an autotransformer. A photocell $11.2 \mathrm{~cm}$ inside the entrance to the shock compartment monitored responding. The avoidance box was in a darkened room provided with $70-\mathrm{dB}$ white noise.

Procedure. All animals were weighed and handled for $2 \mathrm{~min}$ on the morning of the training session. Immediately after handling, each was placed in the passive avoidance box for one habituation trial during which no shock was presented. The animal was then returned to its home cage for $1 \mathrm{~h}$ until its first avoidance trial. Except for the absence of shock, the procedure for the habituation trial was the same as for an avoidance trial. The habituation trial was included in an attempt to make the initial avoidance trial response latencies more homogeneous across species.

Ten animals of each species were given passive avoidance training at each of the shock intensities, $1.0 \mathrm{~mA}$ or $2.0 \mathrm{~mA}$. The response required to avoid shock was to remain in the safe compartment without entering the shock compartment. An avoidance trial began by placing an animal in the lighted safe compartment for $30 \mathrm{sec}$. The guillotine door was then raised concurrently with the start of a timer. When the subject broke the photocell beam in the shock compartment, the door was lowered and the timer stopped. After a 2-sec delay during which the door was lowered, a 3 -sec shock was delivered via the grid floor. The animal was removed $30 \mathrm{sec}$ following shock termination and returned to its home cage. If the animal did not enter the shock compartment within $600.0 \mathrm{sec}$, it was removed from the safe compartment and training was concluded for that subject.

Each subject had one passive avoidance trial at 1-h intervals until the criterion response latency of $600.0 \mathrm{sec}$ was reached or until 10 passive avoidance trials were completed. The number of trials to criterion was recorded for each subject. If an animal did not reach criterion within the 10-tral avoidance session, a score of 11 was assigned as its criterion trial.

\section{Results}

The analysis of habituation-trial latencies for entry into the shock compartment showed no differences 
Figure 3. Number of trials to criterion of passive avoidance performance for gerbils and rats with 1-h intertrial intervals. A score of 11 was assigned if the animal did not reach criterion within the 10 -trial avoidance session.

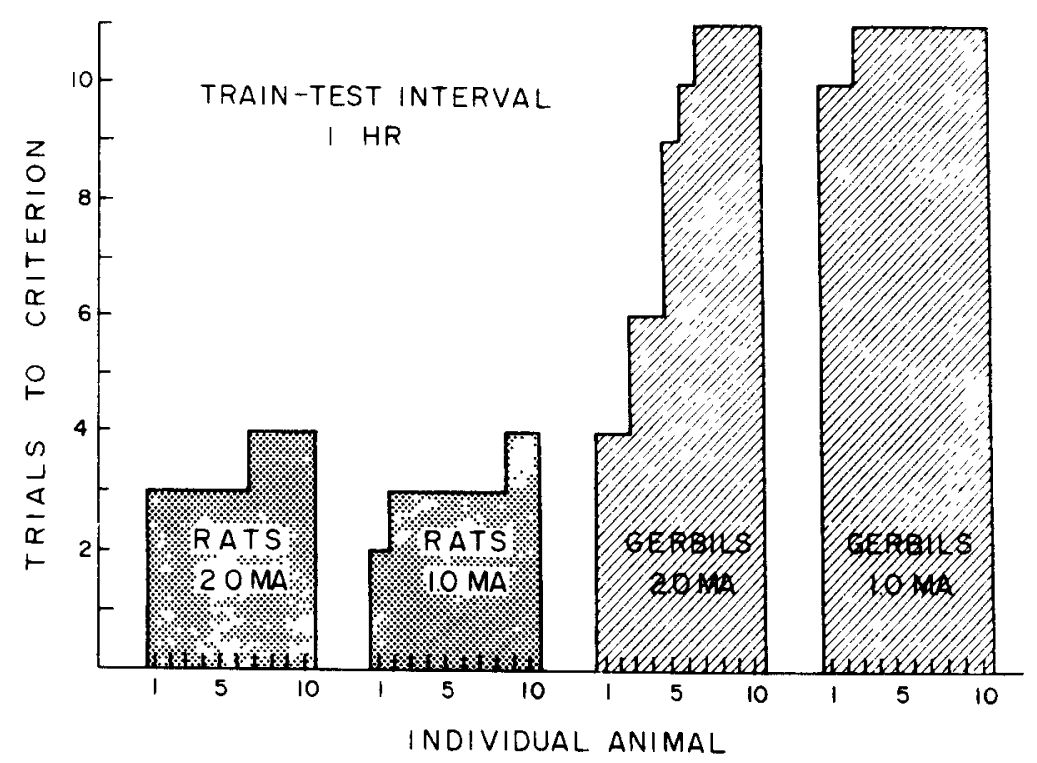

between species $(F<1)$. Similarly, response latencies between species on the first avoidance trial were not reliably different $(F=1.13, d f=1 / 36, p=.30)$.

Trials to criterion of passive avoidance response acquisition are presented in Figure 3. Rats reached criterion in fewer trials than did gerbils $(F=164.23$, df $=1 / 36, p<.001)$. A significant Species by Shock Intensity interaction $(F=8.11, \mathrm{df}=1 / 36, \mathrm{p}<.01)$ indicated that $2.0 \cdot \mathrm{mA}$ gerbils reached criterion in fewer trials than did $1.0-\mathrm{mA}$ gerbils $(\mathrm{F}=6.88, \mathrm{df}=1 / 18$, $\mathrm{p}<.05$ ), whereas no shock intensity differences in number of trials to criterion were found for rats $(\mathrm{F}=1.53, \mathrm{df}=1 / 18, \mathrm{p}=.23)$.

\section{Discussion}

Regardless of shock intensity, rats reached the criterion of staying in the safe side of the avoidance box for $600.0 \mathrm{sec}$ in fewer trials than the gerbils. In contrast to our predictions, gerbils required more shocks than rats to acquire the passive avoidance response at 1-h intertrial intervals. Hence, the contention that gerbils are more sensitive than rats to shock-induced activity suppression was not supported. Presumably, a species which suppresses in activity to shock should require few, not many, shocks to learn to stay. Figure 3 shows that gerbils did not behave in this manner.

\section{EXPERIMENT III}

It is possible that, within the $1-\mathrm{h}$ intertrial intervals of Experiment II, gerbils "recovered" from any unconditioned responses to shock which might have affected avoidance responding under the conditions of Experiment I. To test this possibility, the performance of gerbils and rats was compared in a passive avoidance task with $2 \mathrm{~min}$ between trials. This interval, which more closely approximated that used in the Y-maze study, was thought to preclude intertrial recovery from any shock-induced activity suppression.

\section{Method}

Subjects and apparatus. Ten male Sprague-Dawley rats obtained from the Holzman Company and 10 male gerbils from the laboratory colony were housed and tested in conditions identical to those of Experiment II. The rats were 79-81 days old and weighed $340-385 \mathrm{~g}$. The gerbils were $4-5$ months old and weighed $40-70 \mathrm{~g}$. The apparatus was the same as that used in Experiment II. Shock intensity was $0.75 \mathrm{~mA}$.

Procedure. The procedure was identical to that of Experiment II except for these changes: (1) the first avoidance trial began immediately after the habituation trial; (2) each animal had a $1-\mathrm{min}$ period in the safe compartment prior to raising of the door and a 1-min postshock period, after which the animal was put back into the safe compartment (thus, the interval between shock delivery of one trial and the raising of the door for the next was 2 min plus approximately $10 \mathrm{sec}$ of handling time); and (3) the maximum number of trials for the avoidance session was 15 . If the animal did not reach criterion, a score of 16 was assigned.

\section{Results}

No significant differences between species in habituation trial latencies $(F<1)$ or latencies for the first avoidance trial $(\mathrm{F}=2.83$, $\mathrm{df}=1 / 18, \mathrm{p}=.11)$ were found.

Three gerbils did not reach the criterion of passive avoidance in 15 trials, whereas all rats reached criterion. The seven gerbils that reached criterion did so with a median of 12 trials (range 9.14), whereas rats reached criterion with a median of 3 trials (range 2-8). Analysis of the criterion data showed that rats acquired the passive avoidance response in reliably fewer trials than did gerbils $(F=90.41, d f=1 / 18, p<.001)$.

\section{Discussion}

In these passive avoidance studies, gerbils required a greater number of shocks than did rats to reach a 
criterion of passive avoidance performance at intertrial intervals of $1 \mathrm{~h}$ and $2 \mathrm{~min}$, respectively. While most rats learned to remain in the safe compartment after three crosses to the unsafe side which resulted in shock, most gerbils continued to cross over and receive shock even after 10 trials. Each time they did so, they reacted to shock by flinching, prancing, and defecating. Despite this, many gerbils continued to cross from the safe side into the shock side on the next trials. After these studies, two gerbils tested in the same apparatus with the black compartment as the safe side and with $2 \mathrm{~min}$ between trials performed in the same manner. It is thus clear that gerbils are inferior to rats in acquiring a passive avoidance response. This conclusion agrees with previous passive avoidance comparisons of these species using 24-h train-test intervals (Galvanni et al, 1975; Walters \& Abel, 1971) and using nonshock aversive stimulation (Lippman, Galosy, \& Thompson, 1970).

It is also clear that gerbils do not show suppressed activity to shock, as was suggested by their poor performance relative to rats in $\mathrm{Y}$-maze avoidance acquisition in Experiment I. In fact, just the opposite seemed to be the case, in that gerbils maintained a level of locomotor responding during the passive avoldance sessions which repeatedly exposed them to shock. When placed in the safe compartment of the avoidance box, gerbils showed much more of a locomotor response bias than rats and hence required more shocks to learn the staying response. Experiment IV was designed to determine the effects of this species difference in locomotor behavior on active avoldance performance.

\section{EXPERIMENT IV}

It was suggested by Carey and Fischer (1973) that gerbils are better than rats in two-way active avoidance because they have a greater tendency to explore and/or have a higher activity level. This was also suggested by Galvanni et al. (1975) and Lippman et al. (1970) to explain the relatively poor avoidance performance by gerbils in passive avoldance situations. The findings of Experiments II and III support these assertions that gerbils exhibit a pronounced locomotor bias in avoidance situations.

Why, then, were gerbils inferior to rats in acquiring an active avordance response in the Y-maze in Exper1ment I? Presumably, a locomotor bias would facilitate responding in active avoidance tasks requiring a locomotor response to avoid shock. Recall, however, that the $Y$-maze procedure also required a staying response between trials, in that crosses out of the safe arm were punished. This may have disrupted avoidance acquisition tor gerbils, since their strong locomotor bras would not be compatible with the required avoidance behavior of running only during the CS-US interval and staying cluring the intertrial interval.

On the other hand, gerbils might be expected to avoid as well as or better than rats when intertrial crosses are not punished, since their locomotor bias would then be more compatible with the required avoidance response. This is, in fact, what Ashe and McCain (1972) report. They prevented their animals from traversing the shuttlebox between trials by a door lowered after entry into the safe compartment. Since intertrial crossings were impossible, locomotor responses were never punished and were always compatible with the required avoidance response. Apparently as a result of this, therr gerbils were superior to rats in performing two-way shuttlebox avoidance and as good as rats in performing one-way avordance.

To assess the validity of this 1dea, gerbils and rats were trained under one of two conditions in a shuttlebox active avoidance task. For some subjects, intertrial crosses were never punished since they were confined to the safe side between trials. The other subjects were not confined and received shock if they crossed out of the safe side betwcen trals.

\section{Method}

Subjects. Twenty male Sprague-Dawley rats from the Holtzman Company and 20 male gerbils from Tumblebrook Farms, Brant Lake, New York, were used. The rats were 94-102 days old and weighed $320-36.5 \mathrm{~g}$. The gerbils were 77-91 days old and weighed $40-64 \mathrm{~g}$. The animals were housed and tested in conditions identical to those of Experuments II and III.

Apparatus. The 1wo-compartment box used in the two passive avoidance studies was converted to a shuttle active. avoidance apparatus for use in the present study. The walls and tops of both compartments. as well as both sides of the guillotine door, were painted black. The stimulus light in each compartment was a low-intensity $7 \frac{1}{2}-\mathrm{W}$ light bulb in the center of the compartment top. Each bulb was painted black on the half facing the guillotine door so that light was cast toward the rear of each compartment.

Shock intensity was $1.0 \mathrm{~mA}$. Photocells $11.2 \mathrm{~cm}$ from the entrance to each compartment monitored responding. The avoidance box was in a darkened room provided with $70-\mathrm{dB}$ white noise.

Procedure. All anmals were handled for $2 \mathrm{~min}$ and wetghed on the day before avoldance training began. Thirty avoldance acquisition trials wese then given on each of 3 consecutive days.

Avoidance traning was begun by placing an animal in the lighted side of the avoldance box The other side was not lighted. After $40 \mathrm{sec}$, the lig at $w$ as changed to the other side of the box. The response required to avoid shock was entry into the lighted safe compartment within $10 \mathrm{sec}$ of the light change. After $10 \mathrm{sec}$, shock was intiated and remaned on until the subject entered the lighted safe side. The interval between the time an animal entered the safe compartment and the beginning of the next trial was $40 \mathrm{sec}$

Ten gerbils and 10 rats had the guillotine door rased when the light changed from one side to the other and lowered when a response was made into the safe compartment (the Door animals). The door remained closed during the intertrial interval so that the animal could not cross back into the dark, unsafe compartment. For another 10 animals of each species, the guillotine door remained open throughout the avoidance trials except when an animal was being placed into or taken out of the apparatus (the No Door anmals). If the animal left the lighted safe compariment and broke the photocell beam at the entrance of the dark compartment, shock was initiated and remained on until the animal returned to the lighted side. It should be noted that the use of a light CS differs from the Ashe and McCan (1972) procedure but was required in order to compare the Door ard No Door conditions. 

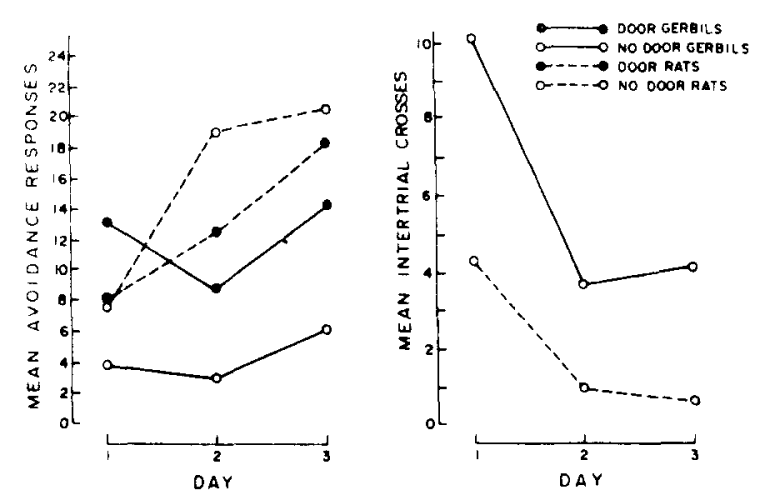

Figure 4. Left panel: Mean avoidance responses per day for gerbils and rats in the shuttlebox. Right panel: Mean intertrial crosses per day for No Door animals.

Two response measures of the animals' performances were recorded in the shuttlebox: (a) avoidances-entry into the lighted safe compartment prior to shock onset, and (b) intertrial crosses-number of times No Door animals left the safe compartment during the intertrial interval and thus received shock.

\section{Resuits}

Avoidances. The left panel of Figure 4 displays the mean number of avoidances per day for each group. In addition to superior overall avoidance performance by rats relative to gerbils $(F=6.51, d f=1 / 36, p<.05)$, a significant Species by Door Conditions interaction $(\mathrm{F}=6.00, \mathrm{df}=1 / 18, \mathrm{p}<.05)$ was found. This interaction represents the findings that Door gerbils made more avoidance responses than No Door gerbils $(F=22.08$, $\mathrm{df}=1 / 18, \mathrm{p}<.001)$, while rat groups did not differ in this manner $(F<1)$. No Species by Door Condition by Days interaction was evident $(F<1)$.

A significant Species by Days interaction $(F=18.20$, $\mathrm{df}=2 / 72, \mathrm{p}<.001)$ represents the different patterns of avoidance responding over days between rats, which increased in mean avoidance, and gerbils, which showed a U-shaped pattern of responding. Rats had a greater number of mean avoidances on Day 3 than Day 1 $(F=47.63, \mathrm{df}=1 / 19, \mathrm{p}<.001)$, whereas gerbils did not $(F<1)$. The decrease in avoidances on Day 2 thus accounts for the reliable days effect $(F=4.47$, $\mathrm{df}=2 / 37, \mathrm{p}<.05)$ detected for the gerbils.

It was of interest to compare the daily avoidance behavior of gerbils and rats within the Door and No Door conditions. The comparison of No Door animals showed that, although the species were not different on Day $1(\mathrm{~F}=2.71, \mathrm{df}=1 / 18, \mathrm{p}=.13)$, rats made more avoidance responses than gerbils on both Day $2(F=20$, $\mathrm{df}=1 / 18, \mathrm{p}<.001)$ and Day $3(\mathrm{~F}=15.62, \mathrm{df}=1 / 18$, $\mathrm{p}<.001)$. For the Door animals, differences between the species in mean avoidances were not reliable for either Day $1(\mathrm{~F}=3.97, \mathrm{df}=1 / 18, \mathrm{p}=.06)$, Day 2 $(\mathrm{F}<1)$, or Day $3(\mathrm{~F}<1)$.

Figure 5 displays the mean number of avoidances per 10-trial block for each day's avoidance session. Such an analysis by blocks of trials was of interest since a similar analysis had detected different patterns of within-session avoidance responding for the two species in the initial $Y$-maze study.

A significant Species by Blocks interaction $(\mathrm{F}=60.26, \mathrm{df}=2 / 72, \mathrm{p}<.001)$ reflected the finding that rats generally increased in mean number of avoidances over blocks whereas gerbils generally decreased in avoidances over blocks. Rats averaged more avoidances in Block 3 relative to Block $1(\mathrm{~F}=35.22$, $\mathrm{df}=1 / 19, \mathrm{p}<.001$ ), while gerbils made fewer avoidances in Block 3 than in Block $1(\mathrm{~F}=28.26, \mathrm{df}=1 / 19$, $\mathrm{p}<.001)$.

The different patterns of avoidance responding within sessions over days accounted for a significant Species by Days by Block interaction $(F=7.32$, df $=4 / 44$, $\mathrm{p}<.001)$. The Species by Door Conditions by Block interaction was not reliable $(F=2.36, \mathrm{df}=2 / 72$, $p=.10$ ).

It was also of interest to compare avoidance performance among groups on the first block of 10 trials of Day 1. This was because Ashe and McCain (1972) in their comparison of gerbils and rats used two blocks of 10 trials per day with a variable time delay between blocks. Hence, for Door animals in the present study, the first 10 trials on Day 1 were highly similar to those run by Ashe and McCain. The present findings can be seen in Figure 5. A significant Species by Door Conditions interaction was found $(F=14$, df $=1 / 36$, $p<.001)$, which reflected a wider difference in mean avoidances between the door conditions for gerbils than for rats. The findings of interest were that Door gerbils had more avoidance responses than No Door gerbils $(F=36.46, d f=1 / 18, p<.001)$, Door rats made more avoidances than No Door rats $(F=10.77$, $\mathrm{df}=1 / 18, \mathrm{p}<.01)$, and No Door gerbils did not differ in number of avoidances from Door rats $(F<1)$. That is, Door gerbils had the greatest number of mean avoidances for the first 10 trials on Day 1, while No Door gerbils and Door rats had more avoidances than No Door rats.
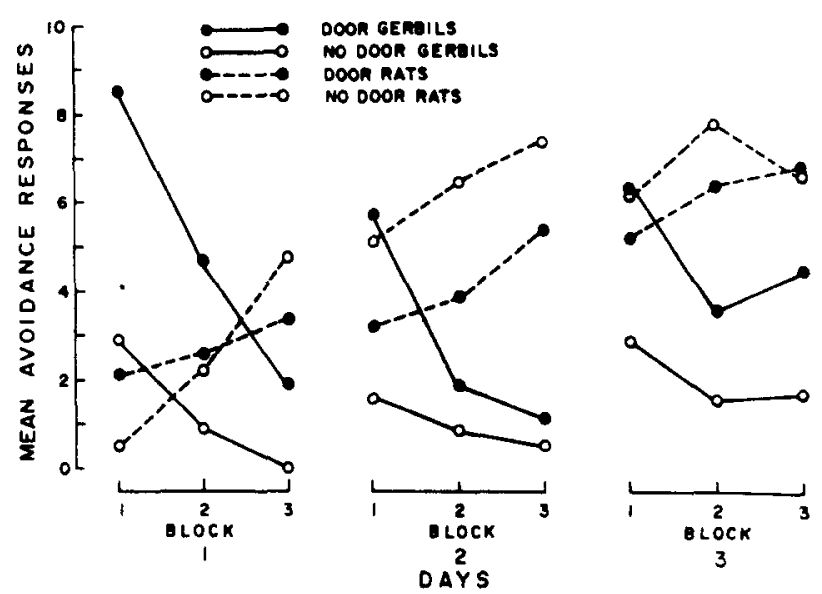

Figure 5. Mean within-session avoidance responses for gerbils and rats in the shuttlebox. 
Intertrial crosses. The right panel of Figure 4 displays the mean number of daily intertrial crosses for No Door gerbils and No Door rats. Gerbils made more intertrial crosses than rats $(F=15.94, \mathrm{df}=1 / 18, \mathrm{p}<.001)$, and the Species by Days interaction was not significant $(\mathrm{F}=2.80, \mathrm{df}=2 / 36, \mathrm{p}=.07)$.

\section{Discussion}

No Door rats avoided better than No Door gerbils in the shuttlebox, whereas Door gerbils and rats did not differ in mean number of daily avoidances made. Thus, gerbils were inferior to rats in two-way shuttlebox avoidance only when intertrial crosses out of the safe compartment were punished, but as good as rats when intertrial crosses were not punished.

This difference between the species in how punishment of intertrial crosses affected avoidance behavior is reflected by the fact that No Door gerbils made significantly fewer avoidances than Door gerbils, whereas Door and No Door rats did not differ on this measure. If anything, Figure 4 suggests a slight facilitatory effect due to the No Door condition for avoidance responding by rats on Day 2. Thus, punishment of intertrial crosses produced poor avoidance responding by gerbils but did not adversely affect avoidance responding in the strain of rats used.

Thus, the reason gerbils were inferior to rats in Y-maze avoidance in Experiment I was apparently because intertrial crosses were punished. The superior two-way shuttlebox avoidance performance by gerbils in the Ashe and McCain (1972) study was probably due as much to the choice of rat strain for comparison with gerbils as to the fact that intertrial crosses were not punished. These authors reported that their male Long-Evans rats made almost no avoidances over the first 3 days of training, whereas the Holtzman rats in the present study avoided on more than $60 \%$ of the trials by Day 3. This view seems reasonable in light of the marked differences in avoidance performance by different rat strains reported by Caul and Barrett (1973).

The right side of Figure 4 shows that gerbils in the No Door condition made many more intertrial crosses than did rats on all 3 days of training. As was found in Experiment $I$, the patterns of avoidance responding within sessions over days were different for the two species. Rats generally increased in mean number of avoidances over blocks and over days. In contrast, gerbils generally decreased in avoidances within sessions and showed a U-shaped pattern of responding over days. Figure 5 shows that this decline in within-session avoidance was especially pronounced for Door gerbils on Days 1 and 2 of training. It should be noted that these findings were not due to the fact that the animals had to run into a safe compartment that was always lighted. Following the conclusion of this study, four gerbils and four rats were run in the Door and No Door conditions with the dark compartment as safe. The same pattern of results were obtained as for the animals run in Experiment IV with the lighted safe compartment.
The present findings apparently reflec 1 the fact that gerbils are more active (Powell \& Peck, 1969) and more exploratory (Glickman \& Hartz, 1964) than rats. As Galvanni et al. (1975) and Lippman et al . (1970) suggested, this no doubt accounts for the passive avoidance differences between the species. It does not necessarily follow, however, that gerbils are superior to rats in active avoidance acquisition. No Door gerbils avoided poorly throughout training and Door gerbils experienced a pronounced decline in avoidance responding over blocks on Day 1 and Day 2. The following observations of the animals during the experiment suggest why this occurred.

When placed in the shuttlebox on Day 1, gerbils immediately began moving about. For No Door gerbils, this usually resulted in an intertrial cross that produced shock. In fact, it was not uncommon for some of these animals to make multiple crosses within the first intertrial interval. This crossing continued at a high rate during the initial trials. Since the intertrial interval was $30 \mathrm{sec}$ longer than the CS-US interval, however, most of these responses did not result in an avoidance of shock but were punished as intertrial crosses. Since this activity was punished, the rate of locomotor responding quickly diminished. No Door gerbils then tended to remain in the safe compartment and soon made only escape responses This is indicated in Figure 5 by the complete absence of avoidance responding during the third block of trials on Day 1.

For Door gerbils, though, this initially high rate of locomotor responding resulted in the high rate of avoidance responding observed during the first 10 trials. Typically, gerbils left the compartment in which they were confined during the intertrial interval immediately after the guillotine door was raised. After the first block of trials, however, the rate of locomotor responding (exploratory behavior?) decreased. With increasing frequency over trials, gerbils received shock for remainIng in the unsafe compartment beyond the 10 -sec avoidance period. By the third block of trials on Day 1, escape responding was the predominant locomotor activity observed.

For both groups of gerbils, the decrease in avoidance responding over blocks probably reflects the punishment and decrease of nondiscriminate locomotor behavior. The fact that gerbils moved about the apparatus at a high rate initially no doubt produced the high rate of avoidance responding and intertrial crossing for Door and No Door gerbils, respectively. However, the avoidance contingency was to traverse the shuttlebox only during the 10-sec avoidance period. Other locomotor responses were punished, did not prevent shock, or were reinforced at inappropriate times. For example, locomotor responses by No Door gerbils during the intertrial interval resulted in shock if made into the unsafe compartment but did not produce shock if confined to the safe side. For both groups, locomotor responses during the 10-sec avoidance period were punished if they did not result in the animal's moving 
into the safe compartment prior to shock onset. Hence their nondiscriminate locomotor behavior exposed the gerbils to an ambiguous reinforcement schedule for locomotor responding and disrupted avoidance acquisition. The upswing in daily avoidances on Day 3 by gerbils, illustrated by the U-shaped pattern of responding in Figure 4, may represent the emergence of locomotor responding controlled by the avoidance contingency.

\section{CONCLUSION}

Gerbils were found to be inferior to rats in two passive avoidance tasks with $1 \mathrm{~h}$ and 2 min between trials, respectively, and in Y-maze and shuttlebox active avoidance tasks when intertrial crosses were punished. The passive avoidance findings are in agreement with past comparisons of these species (e.g., Walters \& Abel, 1971), but the active avoidance findings are not. Gerbils were previously reported to be superior to rats in barpress avoidance tasks (e.g., Walters et al., 1963), and as good as or better than rats in shuttlebox tasks (Ashe \& McCain, 1972) in which intertrial responses were not punished.

In Experiment IV, gerbils that were never punished for intertrial crosses in the shuttlebox had the highest initial rate of avoidance responding among groups. Although this rate declined sharply within the initial daily avoidance sessions, the mean number of overall daily avoidances for these gerbils was not reliably different from their rat comparisons. This indicates that the discrepancy in active avoidance findings noted above is apparently due to the procedural variable concerning whether or not responses during the intertrial interval are punished. Specifically, rats are superior to gerbils in active avoidance acquisition under our conditions when intertrial responses are punished, whereas gerbils are as good as or better than rats when intertrial responses are not punished.

The reason for this is apparently that gerbils avoid poorly when a staying response not compatible with their bias for locomotion is required during the intertrial interval. Since this strain of rats does not exhibit such a locomotor bias, punishment of intertrial crosses does not adversely affect their avoidance performance.

It is clear that species-specific behaviors have interacted with task variables to determine avoidance performance in the present series of studies. In identifying these, this research has reinforced the premise that an analysis of performance differences between species must stress species differences in response repertoire and their precise relationships to task demands.

\section{REFERENCES}

Ashe, V. M., \& McCain, G. Comparison of one-way and shuttleavoidance performance of gerbils and rats. Journal of Comparative and Physiological Psychology, 1972, 80, 293-296.

Barrett, R. J.. Leith, N. J., \& Ray, O. S. A behavioral and pharmacological analysis of variables mediating active-avoidance behavior in rats. Journal of Comparative and Physiological Psychology, 1973, 82, 489-500.

Bolles, R. C. Species-specific defense reactions and avoidance learning. Psychological Review, 1970, 71, 32-38.

Carey. M. A., \& Fischer, G. J. Spatial reversal learning in rats and gerbils. Bulletin of the Psychonomic Society, 1973, 2, 173-174.

Caul, W. F., \& Barrett, R. J. Shuttle-box vs. Y-maze avoidance: The value of multiple response measures in interpreting active avoidance performance. Journal of Comparative and Physiological Psychology, 1973, 84, 572-578.

Galvanni, P. F., Riddell, W. I., \& Foster, $h$. M. Passive avoidance in rats and gerbils as a function of species-specific exploratory tendencies. Behavioral Biology, 1975, 13, 277-290.

Glickman, S. E., \& Hartz, K. E. Exploratory behavior in several species of rodents. Journal of Comparative and Physiological Psychology, 1964, 58, 101-104.

Lippman, L. G., Galosy, R. A., \& Thompson, R. W. Passiveavoidance learning in gerbils and rats. Journal of Comparative and Physiological Psychology, 1970, 73, 269-273.

Powell, R. W., \& Peck, S. Running-wheel activity and avoidance in the Mongolian gerbil. Journal of the Experimental Analysis of Behavior, 1969, 12, 779-787.

Shettleworth, S. J. Constraints on learning. In D. S. Lehrman R. A. Hinde, \& E. Shaw (Eds.), Advances in the study of behavior, Vol. 4. New York: Academic Press, 1972.

Steranka, L. R., \& Barrett, R. J. Kamin effect in rats: Differential retention or differential acquisition of an active-avoidance response? Journal of Comparative and Physiological ance response? Journal of Com
Psychology, 1973, 85, 324-330.

Walters, G. C., A Abel, E. L. Passive avoidance learning in rats, mice, gerbils, and hamsters. Psychonomic Science, 1971, 22, 269-270.

Walters, G. C., Pearl, J., \& Roberts, J. V. The gerbil as a subject in behavioral research. Psychological Reports, 1963, 12, 315-318.

Wise, L. M., \& Parker, E. Discriminative maze learning in the Mongolian gerbil. Psychological Record, 1968, 18, 201-203.

(Received for publication February 19, 1974; revision accepted October 7,1975 .) 